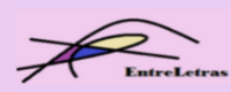

REVISTA ENTRELETRAS (ARAGUAÍNA), V. 12, N. 3, SET./DEZ. 2021 (ISSN 2179-3948 - ONLINE)

\title{
O ROMANCE HISTÓRICO CONTEMPORÂNEO DE MEDIAÇÃO ANA NÉRI, A BRASILEIRA QUE VENCEU A GUERRA (2002): A PRESENÇA FEMININA NA GUERRA DO PARAGUAI (1864-1870)

\author{
THE CONTEMPORARY HISTORICAL NOVEL OF MEDIATION ANA NÉRI, A \\ BRASILEIRA QUE VENCEU A GUERRA (2002): \\ WOMEN'S PRESENCE IN THE PARAGUAIAN WAR (1864-1870)
}

\author{
DOI 10.20873/uft2179-3948.2021v12n3p348-361
}

\section{Rosmere Adriana Vivian Ottonelli ${ }^{1}$ Gilmei Francisco Fleck ${ }^{2}$}

\begin{abstract}
Resumo: As escritas híbridas de história e ficção consideradas romances históricos têm sua trajetória inicial marcada pelos produções do escocês Sir Walter Scott na época do romantismo europeu. Desde sua gênesis esse gênero híbrido vem sofrendo constante mudanças que adaptam essa produção às questões históricas, socias e culturais das diferentes épocas de sua produção. $\mathrm{Na}$ atualidade, ela conta com grande êxito de público em uma modalidae específica que Fleck (2007-2008-2011) classifica como romance histórico contemporâneo de mediação. Nosso propósito ao longo deste texto é expor algumas das cararcterístcias dessa modalidade apontadas pelo pesquisador e confirmá-las na leitura do romance Ana Néri, a brasileira que venceu a guerra (2002), de José Louzeiro. Nossa análise dará ênfase ao fato de que essa modalidade de romance histórico mais atual, embora abandone grande parte dos intuitos desconstrucionistas das produções híbridas de história e ficção mais recentes, não deixa de operar uma leitura crítica do passado. No caso da obra de Louzeiro (2002), ela se dá com relação à participação da mulher na Guerra do Paraguai (1864-1870), cuja perspectiva ficcional buscamos compreender.
\end{abstract}

Palavras-chave: Romance histórico contemporâneo de mediação; Guerra do Paraguai (18641870); personagens femininas de extração histórica; José Louzeiro (2002).

Abstract: The history/fiction hybrid writings deemed historical novels have its origins in the work of the Scottish Sir Walter Scott in the European Romanticism period. Since its genesis this hybrid genre has been going through constant changes that adapt this production to historical, social and cultural matters of different production periods. In present days it counts with great audience success in its specific modality classified by Fleck (2007-2008-2011) as contemporary historical novel of mediation. Our purpose throughout this text is to expose a few characteristics of this modality highlighted by the researcher and confirm them in the reading of the novel Ana Néri, a brasileira que venceu a guerra (2002), by José Louzeiro. Our analysis will point to the fact that, although this most recent modality of historical novels

\footnotetext{
${ }^{1}$ Graduada e mestre em Letras pela UNIOESTE. E-mail: rosmerevivian@yahoo.com.br

${ }^{2}$ Professor Associado da Universidade Estadual do Oeste do Paraná/Unioeste-Cascavel/PR- Brasil, atuante nas disciplinas de Literaturas e Cultura hispânicas, Literatura Comparada e Tradução e Literatura Infantil e Juvenil. Pós-doutor em Literatura Comparada e tradução pela UVigo-Vigo/Espanha. Líder do Grupo de pesquisa "Ressignificações do passado na América: processos de leitura, escrita e tradução de gêneros híbridos de história e ficção - vias para a descolonização". Orcid: 0000-0002-4228-2566 e-mail: chicofleck@yahoo.com.br
} 


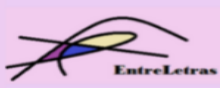

REVISTA ENTRELETRAS (ARAGUAÍNA), V. 12, N. 3, SET./DEZ. 2021 (ISSN 2179-3948 - ONLINE)

lays aside a great deal of its deconstructionist intents of more recent history/fiction hybrids, the critical reading of the past is not left out it. In Louzeiro's (2002) piece, it manifests regarding women's participation in the Paraguayan War (1864-1970), whose fictional perspective we seek to understand.

Keywords: Contemporary historical novel of mediation; Paraguayan War (1864-1870); female characters of historical extraction; José Louzeiro (2002).

Quando Walter Scott escreveu seu romance Waverley (1814) e, em seguida, Rob Roy (1817) e Ivanhoé (1819), inseridos no contexto do Romantismo europeu, estava não apenas imprimindo especificidades às escritas híbridas de história e ficção que se produziam nessa época, mas, também, dando ao próprio gênero romance uma nova vitalidade. Tal forma de escrita, que, conscientemente, mescla história e ficção, atravessou o tempo e ganhou diferentes nuances e configurações de acordo com a estrutura que a sustenta, a linguagem que a faz existir e a ideologia que a impregna.

A possibilidade de revisitar o passado pelas portas da ficção garantiu a muitas nações latino-americanas, em especial, revisar o discurso hegemônico produzido sobre o passado pelos detentores do poder. Entre esses discursos destaca-se aquele que revela como se deram os grandes conflitos bélicos entre os povos. Nesse sentido, cabe mencionar que todo contexto de guerra envolve, predominantemente, a figura masculina, por constituir grande parte dos exércitos oficiais e seus comandos, além de enfatizar seus mentores, governantes dos territórios envolvidos, constituídos, com raras exceções, por homens. Assim, as figuras que se sobressaem como heróis de guerra, devidamente condecoradas, são homens.

Nesse contexto, tanto história quanto literatura, com ênfase ao gênero romance histórico brasileiro, acabam por privilegiar, em seus discursos, personagens masculinos, dada a característica de uma sociedade patriarcal. Raras são as produções que se voltam aos contextos bélicos enfocando neles a participação das mulheres, pois há, nesses eventos e sua recuperação discursiva, espaço garantido ao protagonismo masculino.

Sobre a Guerra do Paraguai, por exemplo, conflito que envolveu a Tríplice Aliança, Brasil, Argentina e Uruguai, com ligações com a Inglaterra, contra o Paraguai, e que se estendeu de 1864 a 1870, são várias as publicações literárias com enfoque à figura masculina. Podemos citar Avante soldados para trás, de Deonísio da Silva (1991), Netto perde sua alma, de Tabajara Ruas (1997), O chasque do imperador, de Simões Lopes Neto (1998), Questão de honra, de Domingos Pellegrini (1996), entre outros. Nas obras citadas, embora a figura 


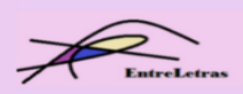

REVISTA ENTRELETRAS (ARAGUAÍNA), V. 12, N. 3, SET./DEZ. 2021 (ISSN 2179-3948 - ONLINE)

feminina esteja presente, por exemplo, na representação das galopeiras, das esposas, das prostitutas, das camareiras das pousadas, elas sempre desempenham um papel secundário.

Apesar de as mulheres fazerem parte do dia a dia da guerra, pouco se menciona sobre elas. De acordo com Pascal (2002, p. 145),

[...] tanto as tropas paraguaias como as brasileiras eram acompanhadas por um verdadeiro exército de mulheres. Esposas, prostitutas, companheiras, mães, que se alimentavam das sobras de seus companheiros, cozinhavam, lavavam, cuidavam dos feridos, abrigavam-se em barracas, distribuíam solidariedade humana, sendo por vezes até maltratadas pelos maridos. Combatiam e morriam esquecidas.

Como vemos, a muitas mulheres não foi dada a chance de permancer longe do conflito, pois as batalhas tomaram grandes proporções territoriais, invadindo campos e cidades; não havia outra opção que não seguir os companheiros combatentes e se tornar mais um deles, ou mesmo seguir os familiares, contexto em que muitas crianças sucumbiram no conflito.

Sobre a mesma guerra, na contramão das publicações que predominam, encontramos um romance que, de certa forma, abre um espaço para o aparecimento dessas figuras femininas: trata-se narrativa Ana Néri, a brasileira que venceu a guerra (2002), de José Louzeiro.

Embora a personagem histórica pertencesse à aristocracia bahiana, esposa e mãe de militares e, portanto, não mais uma das anônimas do conflito, sua participação na Guerra do Paraguai (1864-1870), resgatada pelo romance histórico, colabora para a discussão e valorização da mulher nos destinos de nossa história.

Mesmo que pudesse escolher permanecer em segurança, em seu lar, diferentemente de milhares de mulheres avassaladas pela guerra, Ana opta por adentrar no território do conflito, daí a consideração de ato heroico.

Registros históricos dão conta de que Ana Justina Ferreira Néri nasceu em Vila da Cachoeira do Paraguaçu, Bahia, no dia 13 de dezembro de 1814. Casou-se aos 23 anos com Isidoro Antônio Néri, capitão-de-fragata da Marinha, que estava constantemente no mar. Ana acostumou-se a ter a casa sob sua responsabilidade. Ficou viúva com 29 anos. Em 1843, seu marido morre a bordo do veleiro Três de Maio, no Maranhão. Criou sozinha os três filhos, Justiniano, Isidoro e Pedro Antônio. Os dois primeiros tornaram-se médicos e, Pedro Antônio, militar. 


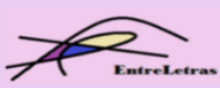

REVISTA ENTRELETRAS (ARAGUAÍNA), V. 12, N. 3, SET./DEZ. 2021 (ISSN 2179-3948 - ONLINE)

Em 1865, ano em que o Brasil integrou a Tríplice Aliança, seus filhos foram convocados para lutar. Em 8 de agosto, escreveu ao presidente da província, oferecendo-se para cuidar dos feridos de guerra. Ao ter o pedido aceito, partiu de Salvador em direção ao Rio Grande do Sul. Com 51 anos, foi incorporada ao Décimo Batalhão de Voluntários e durante toda a guerra prestou serviços nos hospitais militares de Assunção, Corrientes e Humaitá.

Apesar da falta de condições, pouca higiene, falta de materiais e excesso de doentes, Ana Néri chamou a atenção por sua dedicação ao trabalho como enfermeira, por todos os hospitais onde passou. Ana montou uma enfermaria-modelo em Assunção, capital paraguaia, sitiada pelo exército brasileiro. No final da guerra, em 1870, voltou ao Brasil com três órfãos de guerra. Foi homenageada com a Medalha Geral de Campanha e a Medalha Humanitária de Primeira Classe. Dom Pedro II, por decreto, concedeu-lhe uma pensão vitalícia.

Ana Néri faleceu no Rio de Janeiro em 20 de maio de 1880, data em que hoje se comemora o dia do enfermeiro. Outra homenagem à personagem histórica foi concedida por Carlos Chagas, que batizou com o nome de "Ana Néri" a primeira escola oficial brasileira de enfermagem, em 1926.

No romance em questão, Louzeiro (2002) mescla dados e personagens históricos com ficção. Constrói uma narrativa em que humaniza a personagem histórica. Ao organizar a trama, o narrador conta como os fatos poderiam ter sido, ou seja, como a personagem reagiria às ações relatadas, e como os mesmos a afetariam enquanto ser humano.

Nesse sentido, segundo Todorov (1976, p. 211), a narrativa é ao mesmo tempo discurso, pois, “[...] existe um narrador que relata a história; há diante dele um leitor que a percebe. Neste nível, não são os acontecimentos relatados que contam, mas a maneira pela qual o narrador nos fez conhecê-los". Assim, o que mais conta nessa relação é a maneira como o narrador constrói o discurso sobre os acontecimentos, não os acontecimentos em si.

Além de enfatizar a história da protagonista Ana Néri, o narrador, ao mesmo tempo, dá voz a tantos anônimos que viveram esse conflito: escravos, voluntários, mercadores, mensageiros, paraguaios simpatizantes à causa brasileira, e mesmo aos inimigos. Todos aparecem retratados com seus medos e anseios, suas histórias particulares, não mais como números, o que é comum no relato histórico: número de mortos nas batalhas, de ambos os lados, nomes dos que as comandaram, em que local e data aproximadamente estas se deram, e que recursos utilizaram para efetuá-las. No discurso do romance, outra perspectiva pode ser vista, como no fragmento a seguir: 


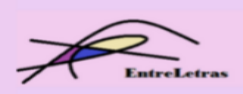

REVISTA ENTRELETRAS (ARAGUAÍNA), V. 12, N. 3, SET./DEZ. 2021 (ISSN 2179-3948 - ONLINE)

Nós marchamos em coluna aberta de pelotões por mais de 20 quilômetros e, em dado momento, tivemos que atravessar um pantanal terrível até chegar à Lagoa Brava. Sou o mais jovem do meu pelotão que pertence ao exército comandado pelo General Osório. Ele é uma figura extraordinária, mãe. Amigo dos oficiais e dos soldados. Não faz distinção. Perto da cidade de Corrientes, num momento de descanso, conheci alguns baianos ilustres. [...] Aqui, por perto dos rios, faz um calor dos infernos e há um moscaral terrível. Quando elas desaparecem, já no final do dia, surgem os mosquitos. Costumamos passar querosene no corpo e outros que não desejam estragar a pele bebem graspa. Quando a gente vai comer, mãe, se não aligeirarmos o abrir e fechar da boca as moscas entram. (LOUZEIRO, 2002, p. 234)

Conforme observamos, as condições do ambiente são relatadas com detalhes que asseguram à narrativa uma contextualização mais próxima daquilo que poderia ter sido o ambiente dessa guerra. Em outras palavras: os pequenos detalhes do dia a dia da personagem central e dos secundários no ambiente da guerra em questão atribuem aos fatos maior subjetividade; o leitor consegue acompanhar e, de certa forma, entender e justificar, por meio principalmente das descrições, o desenrolar dos fatos considerados mais significativos pela história. No fragmento que segue temos mais um exemplo dessa característica da narrativa híbrida:

\begin{abstract}
Francisco e Ramón foram embora. Ana Néri deu uns toques femininos no seu ambiente. Tirou lenços coloridos de uma das malas, amarrou uns nos outros, formando um cordão de cores, que adaptou na divisória de lona. Com grampos e alfinetes pendurou, na mesma divisória, o quadro com os rostos dos filhos. Pedro entre Justiniano e Isidoro. Cansada, estendeu-se no colchonete, que cobriu com um lençol branco. Colocou o travesseiro de capim sob os pés, fez do almofadão seu travesseiro. Seu antigo hábito era dormir com a cabeça alta. Instalou o candeeiro sobre a mala de couro, acendeu o pavio. A luz amarelada foi tomando conta do quarto. Abriu o missal cotidiano. Pôs-se a ler. (LOUZEIRO, 2002, p. 78).
\end{abstract}

E, ainda, o leitor, pela forma de narrativa apresentada, tende a pactuar com a personagem pois, com o avanço dos relatos, passa a conhecer, também, seus sentimentos, conforme constatamos em:

Que bom estar junto com Ramón. Pena que não pudesse ser sua mulher. Já passava dos 50, era viúva, ele mais se aproximava dos 35 , a amizade deveria continuar como estava. Nada de aproximação carnal. Isso era coisa de jovens, como Zomba e Matilde. De outra parte, pelo que podia entender, Ramón Pérez se decidira pela aventura e ela, aos poucos, foi se tornando "a mãe do mundo", título que lhe dera Zacarias e que fora adotado pelos demais internos do São Lázaro. (LOUZEIRO, 2002, p. 130).

Assim, com relação à história de Ana Néri, a diegese cumpre o papel de nos mostrar os possíveis detalhes de sua partida aos territórios da guerra, seus motivos particulares, sua 


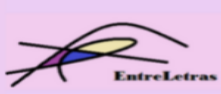

REVISTA ENTRELETRAS (ARAGUAÍNA), V. 12, N. 3, SET./DEZ. 2021 (ISSN 2179-3948 - ONLINE)

permanência no conflito, seus relacionamentos, suas inquietações, sua luta, os percalços que enfrentou, enfim, uma leitura ficcional de sua possível personalidade, como podemos observar no fragmento:

\footnotetext{
O que é a guerra? Por que jovens saudáveis se envolvem em lutas de morte? Qual o princípio que move tudo isso? [...] Herói é quem causa maior destruição ou aquele que está imbuído de missão divina? Ana Néri ficava horas diante do altar, resmungando essas coisas que, aos ouvidos de Matilde, não faziam sentido, mas que, para ela, a viúva de tantas ausências, funcionavam como uma espécie de expiação. (LOUZEIRO, 2002, p. 37)
}

A narrativa, seguindo as características próprias do romance histórico de mediação (FLECK, 2007-2008-2011), organiza-se com uma diegese de desenvolvimento lienar, com um narrador heterodiegético, caracterização utilizada por Genette (1972), que, além de relatar as ações de terceiros, analisa tais ações, os comportamentos, os sentimentos e os pensamentos das personagens, caracterizando-se também como onisciente.

Já no primeiro capítulo do romance, o narrador comenta sobre outras heroínas do interior da Bahia: Joana Angélica, que resistiu ao ataque ao seu monastério por soldados portugueses sob o pretexto de que estaria escondendo revoltosos contra a Junta de Governo; e Maria Quitéria, “[...] que organizou uma companhia feminina, a qual se destacou na luta contra os portugueses que tentaram desembarcar na foz do rio Paraguaçu” (LOUZEIRO, 2002, p. 19), por ocasião do movimento pela Independência do Brasil.

No capítulo II, inicia-se a narração sobre a personagem foco do romance, contando como Ana espera, junto à família, organizando uma grande festa, o retorno do marido, o Capitão de fragata Isidoro Antonino Néri, depois de seis meses no mar:

\footnotetext{
No seu quarto, ajudada pelas costuteiras e a aia Matilde, Ana experimenta o vestido que usaria no reencontro com o marido. [...] Enquanto Ana procurava embelezar-se, José Ferreira punha sua criatividade a serviço da filha que tanto amava [...]. Assim, quando o capitão-de-fragata apontasse na esquina, nem saberia que aquela era sua casa, tão diferente e iluminada estaria. (LOUZEIRO, 2002, p. 23).
}

No entanto, quem chega à residência é outro militar, incumbido de dar a notícia da morte do capitão Isidoro. A partir desse ponto, a narrativa se volta a mostrar a personalidade bondosa e forte de Ana, sempre condescendente com os escravos, sua religiosidade, e como a mesma aprende o ofício de enfermeira, além de descrever seus sentimentos quanto aos filhos e a guerra deflagrada. Na diegese, mesclam-se informações históricas do contexto anterior à Guerra do Paraguai (1864-1870), e o contexto durante a mesma, conforme observamos: 


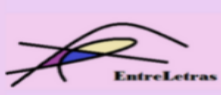

REVISTA ENTRELETRAS (ARAGUAÍNA), V. 12, N. 3, SET./DEZ. 2021 (ISSN 2179-3948 - ONLINE)

“Viúva, Ana Néri se manteve em regime 'de luto fechado’ por seis anos, de 1844 a 1850, o regente do Brasil era Dom Pedro I. Seu pai, Dom João VI, desgostoso com os insucessos políticos, voltou a Lisboa (1821)" (LOUZEIRO, 2002, p. 26). Tais dados, que contextualizam historicamente as ações do romance, atribuem ao mesmo maior credibilidade, em busca de uma verossimilhança convincente.

Essa busca por sustentar a ficção com dados históricos, a organização da diegese seguindo um fluxo narrativo cronológico, a escolha de personagens secundários e o uso de uma linguagem acessível, entre outros aspectos, contribuem para caracterizar o romance de Louzeiro (2002) como romance histórico contemporâneo de mediação.

Esse termo foi cunhado por Fleck (2008) para amalgamar em uma modalidade específica os romances históricos contemporâneos que reúnem tais características, diferenciando-se dos novos romances históricos latino-americanos e das metaficções historiográficas, por um lado e, por outro, dos romances históricos tradicionais, que comungam discursivamente com o discurso hegemônico da história. Tais romances de mediação, ao abandonarem o experimentalismo linguístico e formal dos novos romances históricos latino-americanos e o alto grau de desconstrucionismo das metafieções historiográficas, não deixam de realizar uma leitura crítica do passado - como o fazem essas modalidades -, diferenciando-se, por sua vez, da modalidade tradicional, que dá aval ao discurso historiográfico, mas valendo-se de algumas de suas características, como a linearidade narrativa e o foco centralizado. Desse modo, no romance histórico contemporâneo de mediação "[...] se percebe a manifestação de tentativas de conciliação entre as modalidades antecedentes" (FLECK, 2007, 162). Ainda de acordo com Fleck,

\footnotetext{
[...] em sua elaboração não se abandonam os processos que constituem as características essenciais do novo romance histórico latino-americano, por exemplo o emprego de estratégias como o da paródia e toda a 'sinfonia bakhtiniana', descrita por Menton (1993), além de algumas das questões fundamentais da metaficção historiográfica; porém o texto volta a ser mais linear, já que o emprego das estratégias que constituem os modelos mais experimentalistas passa a ser mais moderado. Isso torna seu processo de leitura mais acessível ao leitor comum, pois não há nele o exagero experimental que caracteriza o modelo de romance histórico das décadas de 80 e 90, especialmente no contexto latino-americano. (FLECK, 2007, p. 162)
}

Além das características já relatadas sobre a modalidade romance histórico contemporâneo de mediação, encontramos uma particularidade na estrutura narrativa do romance ora analisado, que mescla características do gênero narrativo e do gênero dramático, 


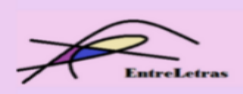

REVISTA ENTRELETRAS (ARAGUAÍNA), V. 12, N. 3, SET./DEZ. 2021 (ISSN 2179-3948 - ONLINE)

com os nomes das personagens antes das falas, sem qualquer introdução por parte do narrador, além da presença de rubricas, conforme exemplificamos em:

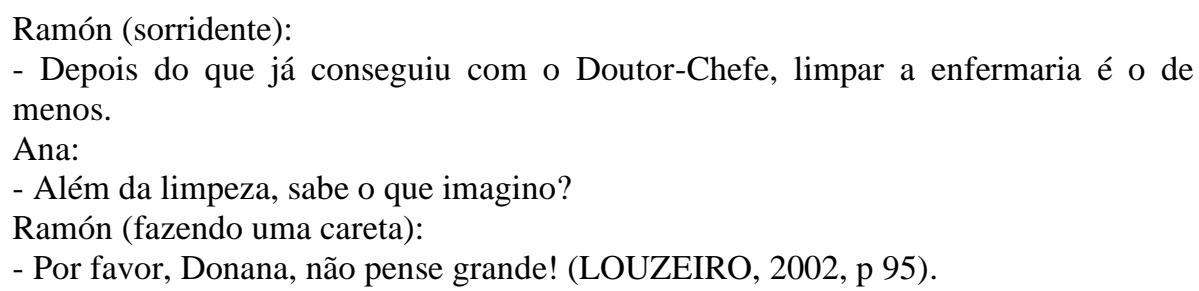

Essa característica atribui maior dinâmica à leitura, colaborando ainda mais com a intenção de torná-la mais simples e objetiva para um leitor menos especializado em questões teóricas sobre o romance histórico, conforme defende Fleck (2011), o que é típico dessa modalidade mais atual de escrita híbrida de história e ficção.

Em resumo, de acordo com estudo elaborado por Albuquerque (2013) sobre essas novas teorias acerca da escrita híbrida de história e ficção contemporâneas, apontadas por Fleck (2007-2008-2011), as características do romance histórico contemporâneo de mediação

\begin{abstract}
[...] são: a construção da verossimilhança, em grande medida abandonada pelas narrativas do novo romance histórico hispano-americano, para conferir um tom de autenticidade aos eventos históricos narrados no romance; a linearidade cronológica dos eventos recriados, fixando-se neles, sem deixar de manipular o tempo da narrativa; privilegiar visões periféricas em relação aos grandes eventos e personagens históricos, como o fazem muitos novos romances históricos $\mathrm{e}$ metaficções historiográficas; linguagem amena e fluida em oposição ao barroquismo e o experimentalismo linguístico dos novos romances históricos; utilização de recursos como a paródia e a intertextualidade assim como de recursos metanarrativos, ou comentários do narrador sobre o processo de produção da obra, sem que estes se constituam no sentido global do texto. (ALBUQUERQUE, 2013, p. 42).
\end{abstract}

A crítica literária muitas vezes busca reunir todas as escritas híbridas de história e ficção sob um mesmo termo agrupador, como o faz, por exermplo, André Trouche (2006), ao denominá-las "narrativas de extração histórica” em sua obra América: história e ficção. Já outros teóricos buscam reuni-las em modalidades nas quais semelhanças na estrutura, na linguagem e na ideologia permitem amalgamá-las, operacionalizando melhor a sua leitura, como ocorre com os termos romance histórico clássico, por Lukács (1977); romance histórico tradicional, por Mata Induráin (1995), Márquez Rodríguez (1991) e Amado Alonso (1995); novo romance histórico latino-americano, por Aínsa (1988-1991) e Menton (1993); 


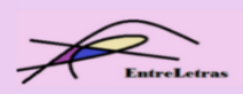

REVISTA ENTRELETRAS (ARAGUAÍNA), V. 12, N. 3, SET./DEZ. 2021 (ISSN 2179-3948 - ONLINE)

metaficção historiográfica, por Linda Hutecheon (1991) e, agora, romance histórico contemporâneo de mediação, por Francisco Fleck (2007, 2008, 2011).

Vale lembrar que, embora as produções sejam classificadas em conjuntos por reunirem determinadas características, estas nem sempre estão contempladas em sua totalidade nas obras representativas de cada uma dessas tendências, o que não as compromete quanto às classificações. Tal fato se deve à liberdade de criação dos autores, ou seja, estes não escrevem um romance para se adequarem a essa ou aquela modalidade, mas assumem certa tendência do contexto histórico-social e seu próprio estilo. Na verdade, os estudos sobre as modalidades se sucedem às obras, daí as novas classificações para as sucessivas produções do gênero romance histórico.

Com relação à modalidade mais recente, descrita e estudada por Fleck (2007-20082011), uma das justificativas apontadas dessa "mediação" entre as modalidades antecedentes é a necessidade de que o gênero se faça também leitura menos "densa", mais prazerosa e de fácil assimilação por um leitor menos experiente acerca das teorias que sustentam a escrita híbrida de história e ficção. Ou seja, há, nessa modalidade mais atual, um certo apelo do mercado a uma produção romanesca menos complexa em comparação ao novo romance histórico latino-americano e à metaficção historiográfica mais recentes.

No caso do romance de Louzeiro (2002), a obra foi produzida depois de um convite de Gilberto Linhares, então presidente do COFEN (Conselho Federal de Enfermagem), com apoio da Mondrian, editora com sede no Rio de Janeiro, para compor a coleção "Anjos de Branco", como uma homenagem às pessoas que se envolveram em causas humanitárias, e em busca da valorização à enfermagem. Fazem parte da mesma coleção A Dor de Cada Um (2001), de Antonio Olinto, Maria da Paz (2000), de Arnaldo Niskier, Guilhermina Enfermeira e Tia da República (2002), de Carlos Nejar, e Os Pecados da Santa (2002), de Marcos Santarrita.

Tal iniciativa de escrita literária sob encomenda recebeu várias críticas, como uma publicada por Marcelo Marthe na Revista Veja Online, em 7 de agosto de 2002, que atribuía a aceitação dos autores ao ganho financeiro, como podemos ver no fragmento:

Presidente do Conselho Federal de Enfermagem (Cofen) e beletrista nas horas vagas, o carioca Gilberto Linhares chegou, no ano passado, a uma conclusão que julgou alarmante: o enfermeiro é um personagem ausente na melhor literatura brasileira. Para remediar a situação, ele resolveu criar uma coleção de romances devotados à categoria. É a série Anjos de Branco, publicada pela editora Mondrian, do Rio de Janeiro, com apoio do Cofen. Em busca do que chama de 'uma plêiade de autores', Linhares foi bater à porta da Academia Brasileira de Letras (ABL). 'Tinha 


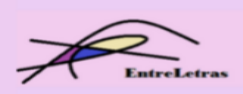

REVISTA ENTRELETRAS (ARAGUAÍNA), V. 12, N. 3, SET./DEZ. 2021 (ISSN 2179-3948 - ONLINE)

certeza de que os acadêmicos se solidarizariam com a causa, porque quase todos que já passaram dos 50 anos aprendem a valorizar mais o nosso trabalho', diz Linhares. [...] Os opositores de Linhares no movimento sindical acham que iniciativas como a coleção Anjos de Branco são uma estratégia para contrabalançar o lado polêmico de sua gestão. [...] Cada autor embolsou entre 4.000 e 10.000 reais para escrever sob encomenda. Mas houve ainda um atrativo extra: a promessa de um público leitor cativo. Órgão fiscalizador da classe, o Cofen tem quase 1 milhão de associados. (MARTHE, 2002, p. 01).

Não nos cabe aqui entrar no mérito de discutir sobre os reais motivos que levaram Louzeiro a produzir a obra aqui analisada, pois não é este o objetivo, e sim enfocar o aspecto de constituir-se como uma das novas modalidades do gênero romance histórico, ao entendermos que cumpre, além de revisitar a história e humanizar a personagem histórica Ana Néri, o objetivo de resgatar a figura feminina na construção de nossa história.

Louzeiro (2002) encontra na personagem todas as características de uma heroína, esta já reconhecida pela história, que reúne abnegação, coragem, determinação, solidariedade, força. Contudo, ao mesmo tempo, são contemplados no romance o medo, a insegurança e o reconhecimento da impotência frente aos desmandos da guerra, proporcionando ao leitor uma perspectiva distinta das grandes batalhas relatadas pelo discurso historiográfico.

Considerando os dados históricos, o autor insere, sobre a formação de Ana como auxiliar de enfermagem, já no segundo capítulo do romance, a seguinte informação:

[...] junto às Irmãs Vicentinas, [...] aprendeu a lidar com os portadores de doenças contagiosas, a produzir remédios caseiros, a lutar com todas as suas forças por aqueles que se encontravam à beira da morte e, em certo momento, chegou a operar a perna de uma ex-escrava, às vésperas de ser afetada pelo tétano. (LOUZEIRO, 2002, p. 30).

E, no decorrer da narrativa, quando Ana já se encontra num dos hospitais de campanha: "Enquanto a operação não era feita, Ana cuidava de Antônio dando-lhe suco de pimentão amarelo com mastruço" (LOUZEIRO, 2002, p. 182).

Suas ações de comando nos hospitais em que trabalhou são constantemente referidas no romance, como a higienização das instalações, em que eram caçados ratos, baratas e até cobras, a abertura nas lonas para arejar, a exigência de banho, corte de barba e cabelo aos feridos, a medicação para exterminar piolhos, e o cuidado com os materiais e instrumentos cirúrgicos, conforme observamos nos fragmentos:

Urina e fezes eram colocadas em um latão e este conduzido à fossa. Devidamente esvaziado, era lavado e desinfetado a fogo, conforme orientação de Ana Néri. [...]. A assepsia do material utilizado no São Lázaro, desde que Ana Néri lá chegou, 


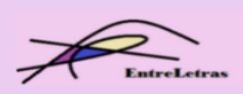

REVISTA ENTRELETRAS (ARAGUAÍNA), V. 12, N. 3, SET./DEZ. 2021 (ISSN 2179-3948 - ONLINE)

transformou-se em uma de suas preocupações. Sabia, como ninguém, que os germes patogênicos constituíam o grande perigo numa enfermaria lotada como aquela, onde estavam centenas de hospitalizados, todos na faixa de 18 a 35 anos. (LOUZEIRO, 2002, p. 183).

Desse modo, a narrativa descreve as condições precárias nas quais atuava a protagonista, que não media esforços para que as calamidades fossem abrandadas e o mínimo a fazer em tais condições era o máximo possível e, provavelmente, o suficiente para salvar muitas vidas e amenizar dores atrozes. Nesse sentido, o romance evidencia as ações da protagonista, como podemos verificar em:

O tratamento para queimaduras, no São Lázaro, era de pobreza franciscana. Restringia-se a pomadas, unguentos, manteigas, inclusive de cacau - Ana trouxe alguns potes consigo - sumo de certas folhas e flores: mamoeiro, hortelã. [...] Júlio apenas ouvia o que Ana dizia. [...] O destino dele e de outros 200, em estado crítico, estava longe de ser animador. Teriam que aguardar a reação orgânica, tendo Ana Néri como fada madrinha. (LOUZEIRO, 2002, p. 219).

Conforme observamos, mesmo diante das maiores dificuldades, a personagem não desiste de lutar pela vida de seus compatriotas, e mesmo de paraguaios que, por algum motivo, também se encontravam na enfermaria do São Lázaro, ou mesmo no isolamento, sob tortura. Diante da escassez de medicamentos e demais condições humanas e estruturais, nas palavras do autor (2002, p. 219), Ana trazia “[...] o elixir que só ela sabia administrar: esperança".

Além de descrever as ações e reações diante do caos da guerra, Louzeiro (2002) introduz, na voz da personagem ficcional, uma crítica ao sistema escravocrata brasileiro da época:

\footnotetext{
Você já percebeu que os paraguaios chamam os brasileiros de criollos? Sabe por quê? Sempre que um nobre de meu país é intimado a dar sua contribuição à pátria, ele pode optar. Em vez de vir ou mandar os filhos, manda os escravos. E o mais engraçado. Todos aqui chegam na condição de voluntários. Não vieram por que tenham se alistado no exército. Vieram por indicação do dono que, nesse caso, providencia a alforria. Olhe só o absurdo. Lá no Brasil, na paz, o negro é escravo. Para morrer aqui, nestas lonjuras, ele se torna cidadão. (LOUZEIRO, 2002, p. 178).
}

Também critica a postura dos comandantes dos acampamentos, estes preocupados em mostrar serviço somente quando visitados por uma autoridade maior, no caso do excerto, a visita do Duque de Caxias: “[...] Dr Amoedo estava transformado [...] assumira de vez sua postura de mandão. Assemelhava-se em tudo a um capataz de uma fábrica de bonecos que, de 


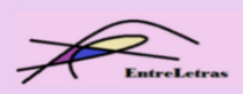

REVISTA ENTRELETRAS (ARAGUAÍNA), V. 12, N. 3, SET./DEZ. 2021 (ISSN 2179-3948 - ONLINE)

repente, deveriam mostrar-se com ótima aparência, em função do ilustre visitante que estava a caminho." (LOUZEIRO, 2002, p. 144).

E, além disso, denuncia a intenção de alguns enriquecerem diante das oportunidades que se configuraram diante das circunstâncias da guerra:

\begin{abstract}
Cada um, por aqui, está procurando safar-se como pode, a fim de voltar para casa duplamente vitorioso: herói porque ajudou a esmagar o ditador Solano López, e rico, bolsos cheios de dinheiro e jóias (sic), resultado dos saques nas cidades abandonadas.[...] primeiro nos apoderamos das pesquisas que estudiosos paraguaios e ingleses desenvolviam sobre doenças tropicais [...] Patentearemos os remédios, ganharemos prêmios, faremos palestras na Europa, seremos bajulados por um batalhão de acadêmicos que nunca inventaram nada. O Imperador nos condecorará como luminares da ciência! [...] A partir de amanhã, providenciarei para conveter em barras todo o ouro que já consegui amealhar. (LOUZEIRO, 2002, p. 199).
\end{abstract}

Assim, ao contemplar a face mais humana das personagens, inclusive a face desonrosa de heróis históricos, Louzeiro (2002), por meio da narrativa ficcional, consegue preencher alguns dos vazios deixados pela história oficial, a qual somente destaca os nomes, os feitos e as datas desse evento sangrento de nossa história.

E, nessa dinâmica, resgata, como já salientamos, a importância da mulher na construção da história, o que em geral é desconsiderado pela maioria dos escritos híbridos que mesclam literatura e história - os quais se voltam predominantemente ao universo masculino, refletindo, em parte, o discurso histórico, que privilegia personagens que se colocaram no comando das ações decisivas para uma comunidade, país ou mundo, estes, quase sempre, homens.

Desse modo, o romance histórico contemporâneo de mediação, ao privilegiar figuras "secundárias" que vivenciaram os eventos históricos, possibilita que novas perspectivas desses fatos do passado sejam geradas e também a consciência de que a história é feita não apenas por uma camada detentora do poder, mas por todos os sujeitos que movem as forças sociais, que operam as mudanças necessárias ao avanço humano. Entre esse contingente estão, sem dúvida, inúmeras mulheres, embora sua participação tenha sido, muitas vezes, omitida pelo discurso historiográfico que privilegia a figura masculina, que é assim exaltada e glorificada a fim de criar grandes heróis.

\title{
Referências
}




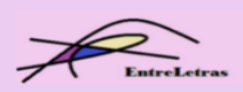

REVISTA ENTRELETRAS (ARAGUAÍNA), V. 12, N. 3, SET./DEZ. 2021 (ISSN 2179-3948 - ONLINE)

ALBUQUERQUE, A. de B. Narrativas canudenses: conflitos além da guerra. 175f. Dissertação (Mestrado em Letras) - Universidade Estadual do Oeste do Paraná - UNIOESTE, Cascavel, 2013.

AÍNSA, F. El proceso de la nueva narrativa latinoamericana de la historia y la parodia. El Nacional, Caracas, p. 7-8, 17 dic. 1988.

AÍNSA, F. La nueva novela histórica latinoamericana. México: Plural, 1991.

ALONSO, A. La nueva novela histórica latinoamericana. México: Plural, 1991.

BIOGRAFIA de Ana Néri. Disponível em http://www.e-biografias.net/ana_neri/ Acesso em 22 de novembro de 2014.

FLECK, G. F. A Conquista do "entre-lugar": a trajetória do romance histórico na América. Gragoatá, Niterói, n. 23, jul./dez.2007, p. 149-167.

FLECK, G. F. O romance, leituras da história: a saga de Cristóvão Colombo em terras americanas. Tese. Universidade Estadual Paulista Julio de Mesquita Filho, Faculdade de Ciências e Letras. Assis, SP, 2008.

FLECK, G. F. Gêneros híbridos da contemporaneidade: o romance histórico contemporâneo de mediação - leituras no âmbito da poética do descobrimento. In: RAPPUCCI, C.A; CARLOS, A. M. (Orgs.). Cultura e Representação - ensaios. Assis/SP: Triunfal, 2011.

GENETTE, G. Discurso da narrativa. Lisboa: Vega, s/d. Figuras. São Paulo: Perspectiva, 1972.

HUTCHEON, L. Poética do pós-modernismo. Trad. Ricardo Cruz. Rio de Janeiro: Imago, 1991.

LOPES NETO, J. S. Contos gauchescos. 2. ed. São Paulo: Ática, 1998.

LUKÁCS, G. La novela histórica. Trad. Jasmin Reuter. 3. ed. México: Era, 1977.

MÁRQUEZ RODRÍGUEZ, A. Evolución y alcances del concepto de novela histórica. In: Historia y ficción en la novela venezolana. Caracas: Editora Monte Ávila, 1991, p. 15-54.

MATA INDURÁIN, C. Retrospectiva sobre la evolución de la novela histórica. In: SPANG, K. et al. (ed.). La novela histórica. Teoría y comentarios. Barañain: EUNSA, 1995, p. 13-63.

MENTON, S. La nueva novela histórica de la América Latina: 1979-1992. México D. F: Fondo de Cultura Económica, 1993.

NEJAR, C. Guilhermina - Enfermeira e Tia da República. São Paulo: Mondrian, 2002.

NISKIER, A. Maria da Paz. São Paulo: Mondrian, 2000.

OLINTO, A. A dor de cada um. São Paulo: Mondrian, 2001.

PASCAL, M. A. M. As mulheres na guerra do Paraguai. Disponível em:

http://www.mackenzie.com.br/fileadmin/Publicacoes-artigos .pdf (145-153). Acesso em 22 de novembro de 2014.

PELLEGRINI, D. Questão de honra - romance intertextual com A retirada da Laguna do Visconde de Taunay. Curitiba: Fundação Cultural, 1996.

RUAS, T. Netto perde sua alma. 3. ed. Porto Alegre: Mercado Aberto, 1997.

SANTARRITA, M. Os pecados da Santa. São Paulo: Mondrian, 2002. 


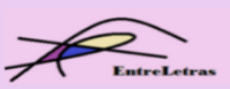

REVISTA ENTRELETRAS (ARAGUAÍNA), V. 12, N. 3, SET./DEZ. 2021 (ISSN 2179-3948 - ONLINE)

SILVA, D. da. Avante soldados para trás. São Paulo: Siciliano, 1991.

TROUCHE, A. América: história e ficção. Niterói, RJ: EDUFF, 2006.

Recebido em 04 de novembro de 2021 Aceito em 11 de janeiro de 2022 